\title{
Todos los caminos llevan a Roma
}

\author{
All Roads Lead to Rome
}

\begin{abstract}
Andrés Rosler
Resumen: Las réplicas del autor a los comentarios críticos se ordenan en tres secciones: (1) retrato (la fisonomía del retratado mismo, que incluye consideraciones metodológicas sobre cómo está hecho el retrato); (2) fuego amigo (es decir, proveniente de autores que profesan el discurso republicano); y (3) fuego enemigo o en todo caso indiferente (autores que, al menos en esta ocasión, no hacen profesión de fe republicana).
\end{abstract}

Palabras claves: Metodología, republicanismo clásico, igualitarismo, neorepublicanismo

\begin{abstract}
The author's replies to critical remarks are arranged in three sections: (1) portrait (the physiognomy of the portrayed himself, which includes methodological considerations on how the portrait is made); (2) friendly fire (that is, from authors who profess the republican discourse); and (3) enemy or in any case indifferent fire (authors who, at least on this occasion, do not make a profession of republican faith).
\end{abstract}

Key-words: Methodology, classic republicanism, egalitarianism, neorepublicanism

Doctor en Derecho (Oxford). Profesor de Filosofía del Derecho en la Facultad de Filosofía y Letras de la Universidad de Buenos Aires. Investigador del CONICET, Argentina. Correo electrónico: andres.rosler@gmail.com 
Debo comenzar agradeciéndole a Discusiones en general, y a Juan Iosa y Julio Montero en particular, por esta gran oportunidad de responder a los trabajos presentados por varios distinguidos colegas sobre Razones Públicas. Seis conceptos básicos sobre la república, Katz Editores ( $R P$ a partir de aquí).

Se trata de una discusión que se remonta a un inolvidable fin de semana a fines de julio del año pasado en Río Ceballos. Les estoy muy agradecido a los organizadores y a los asistentes del seminario en general, tanto por la posibilidad de discutir el libro, como por la amabilidad que me han dispensado. Me han hecho sentir como en casa, aunque es una manera de decir ya que en casa no me tratan tan bien.

El orden de mi respuesta a los muy interesantes trabajos sobre Razones Públicas presentados en Discusiones es el siguiente: 1) retrato (la fisonomía del retratado mismo, que incluye consideraciones metodológicas sobre cómo está hecho el retrato); 2) fuego amigo (es decir, proveniente de autores que profesan el discurso republicano); y 3) fuego enemigo o en todo caso indiferente (autores que, al menos en esta ocasión, no hacen profesión de fe republicana).

Siguiendo entonces la taxonomía propuesta, me da la impresión de que el trabajo de Emmanuel Biset ("Razones Políticas") trata fundamentalmente sobre la manera deficiente en que encaré el retrato del republicanismo y por lo tanto sobre el retrato en sí mismo, por lo cual empiezo respondiéndole a él.

Paula Hunziker ("Notas arendtianas sobre La República de Rosler"), también alberga interesantes objeciones sobre el retrato pero además, y fundamentalmente, defiende una concepción alternativa de republicanismo, por lo cual su texto es ideal para la transición desde la metodología hacia el contenido del libro, sin apartarnos del republicanismo.

Guillermo Lariguet ("La exigencia retórica in utramque partem y el tema del escepticismo"), por su parte, desarrolla muy eruditamente la relación entre retórica y escepticismo en la tradición clásica, sin dejar de dar a entender que se siente bastante cómodo con la idea de que la política es básica aunque no solamente conflicto. De ahí que mi breve respuesta a su trabajo también figure en la transición desde la discusión metodológica hacia la sustantiva, es decir, acerca de qué hacer con el republicanismo. 
Me parece que, a muy grandes rasgos y tal como lo indica el título de su trabajo ("Más allá del republicanismo clásico"), Romina Rekers está dispuesta a conceder que el republicanismo clásico está descripto en el libro de un modo bastante fidedigno. Lo que le interesa mostrar, en realidad, es que el republicanismo clásico ha sido superado por el neorepublicanismo contemporáneo, de ahí que proponga ir todavía "más allá del republicanismo clásico". Me parece entonces que existen buenas razones para responderle a Rekers después de dejar atrás la discusión sobre el retrato pero sin abandonar el territorio republicano.

El texto de Anna Richter ("El rol de las virtudes en el republicanismo") permite el inicio del éxodo hacia el territorio adversario, ya que su propuesta-al menos a juzgar por esta publicación-es la de estudiar la relevancia de la doctrina clásica del republicanismo sobre la virtud para las sociedades contemporáneas, sin dejar de mostrar ciertas reservas al respecto.

Finalmente, voy a tratar de responder las cuestiones planteadas por Luciano Venezia ("El republicanismo frente al liberalismo igualitario") y Matías González del Solar ("Republicanismo y vida privada"), quienes han expresado sus fundamentadas dudas acerca de la superioridad republicana, al menos en relación a ciertas cuestiones, lo cual a los efectos de esta respuesta es considerado como "fuego enemigo". El punto esencial de Venezia es que Razones Públicas no le hace justicia al liberalismo igualitarista, el cual puede hacerle sombra al republicanismo en la lucha contra la dominación. González del Solar, por su parte, señala algunos flancos débiles del republicanismo en relación a la vida privada.

Como alguna vez dijera Groucho Marx, antes de empezar tengo algo importante que decir. Por razones de espacio obviamente no puedo hacer justicia a todas las cuestiones planteadas en estos trabajos, sino que debo seleccionar algunos puntos. Me voy a concentrar entonces fundamentalmente en las objeciones, para luego, a la mejor usanza humanista, pasarme yo mismo de bando en medio del debate, sumándome de este modo al fuego contra el republicanismo. 


\section{Retrato}

Según el trabajo de Emmanuel Biset ("Razones Políticas"), "el problema por excelencia del libro" es "la relación entre historia y juicio". Inmediatamente a continuación aparece la razón: "aquí aparece una tensión en el libro, no diría una contradicción para no ser excesivo, que parece no resolverse: al mismo tiempo que se indica que la historia no puede dar respuesta al presente, el libro no es sino una reconstrucción histórica que busca dar elementos taxativos para calificar qué es y qué no es republicano como elemento de juicio en el presente político". En este mismo sentido, Biset sostiene que el libro "otorga la grilla infalible para rastrear y detectar falsos republicanos en el mundo contemporáneo" y que "el libro no es sino un salto de la historicidad a lo ideal" (sección 2).

Biset tiene mucha razón en que el libro contiene un test para detectar republicanos. El comienzo mismo del libro, de hecho se trata del primer párrafo de la introducción, reza: "La tesis central de este libro es muy simple. Un retrato fiel del republicanismo debe contener al menos cinco rasgos fundamentales: libertad, virtud, debate, ley y patria. Estos cinco rasgos, a su vez, son incompatibles por definición con el perfil aguileño y ultrapersonalista de César, o de su equivalente moderno, el cesarismo. Esta breve lista de rasgos sirve asimismo como un test infalible para detectar republicanos" ( $R P$, p. 9, énfasis agregado). La idea del test, que solo aparece una vez al comienzo del libro y cuya misión principal es la de tratar de captar la atención del lector (que al menos en este caso ha tenido éxito), es mencionada por Biset en cuatro oportunidades (v., v.g., secciones 2 y 3 ).

También tiene mucha razón Biset al señalar que en el libro se indica que "La historia de las ideas es de gran ayuda-entre otras cosas-para cuestionar el menú contemporáneo de platos políticos, pero la decisión acerca de cuál plato debe figurar en el menú es siempre contemporánea. La historia del pensamiento no puede pensar por nosotros" (RP, p. 19) ${ }^{1}$.

1 En rigor de verdad, en esto sigo a John Dunn: "el tiempo pasado no puede ocupar el lugar del tiempo presente. Al final tenemos que juzgar nosotros mismos tan sobriamente como podamos" (cit. en $R P$, p. 19). 
Sin embargo, no advierto cuál es la contradicción o la tensión. El inicio del libro no solo busca captar lectores, sino que además indica que si un discurso político comparte los rasgos del retrato, entonces se puede hablar de un parecido entre ambos, del mismo modo que se puede hablar del parecido entre un retrato y una persona diferente a la que posó para ese retrato. Por ejemplo, en el primer acto de Tosca de Puccini, el retrato que pinta Mario Cavaradossi en Sant'Andrea della Valle era el de la Magdalena, pero como la retratada se parecía mucho a la Marquesa Attavanti, eso ocasiona precisamente los celos de Tosca, la protagonista. Si bien las personas y las épocas son distintas, el parecido es innegable.

El retrato y el test, entonces, son metáforas, pero bastante útiles. Por más que el libro intente ofrecer un retrato clásico del republicanismo, puede ser que alguien o algo hoy en día se vea reflejado en dicho retrato y tengan, por lo tanto, cierto parecido o aire de familia con dicho retrato. Nadie dice, sin embargo, que existe una contradicción entre el retrato y el parecido, sino todo lo contrario.

En todo caso, lo que Biset señala, "el libro no es sino una reconstrucción histórica que busca dar elementos taxativos para calificar qué es y qué no es republicano como elemento de juicio en el presente político" (sección 2), sería un problema si el libro pretendiera ser sobre el republicanismo sin más, o si sostuviera que existe un republicanismo para todas las épocas. Sin embargo, tal como figura en la segunda página de la introducción y se puede encontrar en casi todas las páginas del libro, "Nuestro retrato del republicanismo es de raigambre definitivamente clásica" ( $R P$, p. 10, énfasis agregado).

La frase de Biset ganaría bastante en precisión si, por ejemplo, estuviera formulada de este modo: "el libro no es sino una reconstrucción histórica que busca dar elementos taxativos para calificar qué es y qué no es republicano en el sentido clásico de la expresión como elemento de juicio en el presente político para detectar qué o quién es republicano en el sentido clásico de la expresión". Pero en tal caso, de nobis fabula narratur, lo cual es, en gran medida, el punto del libro.

Ciertamente, el retrato es clásico "en más de un sentido". Por un lado, lo es "en términos cronológicos, ya que todos los temas a discutir figuran predominantemente en la obra de Cicerón, Salustio, Tito Livio, etc." ( $R P$, p. 10). Pero, obviamente, decir que algo es un clásico, si bien suele implicar 
que estamos frente a "un partido aparte" como dicen los comentaristas de fútbol, también sugiere que estamos en presencia de algo valioso: "la obra de pensadores cronológicamente clásicos como Cicerón, Salustio o Tito Livio, puede ser clásica además en sentido valorativo, ya que en lugar de haberse vuelto obsoleta, ha devenido digna de ser leída y discutida en todas las épocas" ( $R P$, p. 11).

Biset podría replicar que, en el fondo, por más histórica que pretenda ser la reconstrucción o la presentación, el solo hecho de escribir sobre el republicanismo clásico es una manera de invitar a que el plato, por antiguo que sea, figure en el menú contemporáneo de teorías políticas. Hablando de menús, lo que está en cuestión puede ser ilustrado apelando a una historia que solía contar Norman Erlich. Un israelí vuelve a su país con muchos artefactos electrónicos y cuando el oficial de aduanas le pregunta si trae algo para declarar, el israelí le contesta: "comida para pollos". Asombrado, el oficial de aduana le responde con una pregunta: “¿cómo que comida para pollos?", a lo cual el israelí responde: "sí, comida para pollos. Yo se los doy de comer a los pollos, y si no lo quieren comer, lo vendo". Creo que Biset dice algo parecido sobre el retrato, pero con otras palabras y haciendo referencia a Derrida: "su carácter performativo adquiere fuerza al postularse como un enunciado sólo constatativo" (sección 3).

En la primera página del libro se puede leer, sin embargo, que "una descripción de los rasgos o conceptos básicos de un discurso político no sirve solamente un propósito estético, sino que constituye a la vez una agenda, i.e. un recordatorio de cuestiones que toda persona interesada en el republicanismo se debería plantear" ( $R P, 9-10)$. De hecho, "gracias a las investigaciones de, v.g., Quentin Skinner sobre el republicanismo, esa muy rica historia ha sido revitalizada a tal punto que se ha convertido en una de las opciones en boga del menú contemporáneo de teoría política, tal como lo muestra la obra de Philip Pettit" (RP, p. 11). En otras palabras, el republicanismo neo-romano ya se sirve en varios establecimientos gastronómicos. Pero, siempre y cuando el retrato sea fiel y los clientes medianamente razonables, no tiene sentido sospechar que los segundos-o los oficiales de aduana para el caso-están siendo engañados.

De hecho, en la introducción de Razones Públicas figura que "En este libro nos proponemos exponer un retrato del republicanismo 'con verrugas 
y todo', como se suele decir en inglés, i.e. con todos sus defectos" $(R P, 19)$. Es por eso que el libro trata prácticas e instituciones como la esclavitud, la censura, la dictadura, el miedo al enemigo, etc., ya que, insisto, pretende ser un retrato fiel del republicanismo clásico.

Otro problema del libro, sostiene Biset, es que "no se dirige a mostrar la singularidad histórica que permite mostrar una pluralidad de republicanismos" (sección 2). En otras palabras, "El retrato fiel del libro no se atiene a momentos históricos, a mostrar la singularidad de un cierto contexto, los debates intelectuales que posibilitan la emergencia y transformación de los conceptos políticos, sino en vistas a la fijación de rasgos ideales" (sección 3).

Sin embargo, me veo obligado a repetir, el libro satisface la exigencia de la singularidad histórica ya que trata sobre el republicanismo clásico en sentido histórico, y la enorme mayoría de las notas que figuran en el libro obedecen al propósito de indicar por qué, a pesar de lo que dice Biset, no incurro en "cesarismo metodológico" (sección 3), es decir, el retrato en cuestión no es una forma de expresionismo cesarista, sino un retrato en el sentido, otra vez, clásico de la expresión, una pintura que refleja cierto parecido. La relación de parecido no depende de las intenciones, sino de la similitud entre los objetos que componen la relación.

En realidad, es debido a que existen varios republicanismos que el libro se concentra en uno de ellos, el clásico. En la misma introducción del libro queda claro que se puede hablar de republicanismo en términos más amplios y más estrictos. "Por un lado, como se puede apreciar, 'república' puede hacer referencia de un modo bastante amplio a los asuntos públicos en general, lo cual explica, por ejemplo, que Cicerón, en una decisión que iba a ser muy bien recibida hasta el día de hoy, tradujera el título del diálogo de Platón Politeia precisamente como República” (RP, p. 27). Pero, “república' en un sentido estricto, bastante más demandante normativamente hablando, se refiere al objeto que nuestra discusión se propone retratar, i.e. a un régimen político cuyo valor primordial es la libertad, que depende de la virtud cívica, gira alrededor del debate, sostiene el imperio de la ley, exige una actitud patriótica y es fuertemente antipersonalista" ( $R P$, p. 28). Otra vez, "Este libro propone entonces una agenda republicana en el sentido más demandante de la expresión" $(R P, 29)$. Así y todo, la última sección 
del capítulo 3, "en el principio era el conflicto", trata sobre las diferencias al interior del modelo republicano clásico.

En cuanto a que para Biset "El punto central al respecto, me atrevo a decir uno de los motivos que orientan todo el libro, es mostrar que el cesarismo es incompatible con cualquier republicanismo" (sección 2), incluso si supusiéramos que esto es cierto, esto es, que lo que me llevó a escribir el libro es mostrar que el cesarismo y el republicanismo clásico son incompatibles, mis intenciones son nuevamente irrelevantes para determinar si el cesarismo y el republicanismo clásico son incompatibles. A veces, hasta un paranoico puede ser perseguido, tal como lo reflejan las mejores películas sobre el tema. Nuevamente, son las fuentes de las que emana el republicanismo clásico las que nos proveen de la evidencia para juzgar si el cesarismo y el republicanismo clásico son incompatibles.

Biset cree que el retrato clásico del libro pasa por alto que pueden existir "formas de personalismo no ordenadas en vistas a la dominación o la interferencia arbitraria” (sección 3). Sin embargo, hay un capítulo, el sexto, que trata precisamente esta cuestión, particularmente en la sección sobre la dictadura (un invento del republicanismo clásico por lo demás). El problema con César, en todo caso, fue que se convirtió en un dictador vitalicio o perpetuo, lo cual tal vez sea muy recomendable en sí mismo, pero es una contradicción en sus términos desde el punto de vista del republicanismo clásico.

Por lo demás, Biset no ofrece evidencia alguna que muestre por qué, en realidad, César fue el salvador de la república antes que la persona que expidió su certificado de defunción ${ }^{2}$. De hecho, incluso asumiendo que mi método es el equivocado-o peor todavía, que sea inexistente-de ahí no se sigue necesariamente que el retrato sea falso. Para poder determinar eso hay que mostrar que el republicanismo clásico es diferente al retratado. Hasta un reloj analógico que no funciona puede dar la hora correctamente dos veces al día.

Biset indica una segunda tensión o paradoja: "Esto me lleva, en segundo lugar, a señalar una paradoja que estimo aún mayor: por los motivos enunen todo caso moribunda. 
ciados el propósito que anima el libro parece ser anti-republicano" (sección 3). A primera vista, suponiendo que mi propósito haya sido el de defender el republicanismo clásico, la paradoja podría consistir en que así y todo el libro es tan malo que en el fondo sirve una meta anti-republicana, al menos en lo que atañe al republicanismo clásico.

A juzgar por la frase siguiente, "la intención del libro tal como se establece en el punto precedente abre el debate público sobre el republicanismo de un modo extraño: busca definirlo de modo infalible" (sección 3), creo que, bien entendido, el punto de Biset es el siguiente: ¿cómo puede ser que alguien diga a la vez que el debate es constitutivo de la política y a la vez esta misma persona pretende tener razón? ${ }^{3}$ En otras palabras, si yo fuera consecuente, o mejor dicho si lo fueran quienes creen que el debate es constitutivo de la política, deberían reconocer a la vez que no pueden tener razón. En realidad, se trata de una cuestión que afecta a todo aquel que se dedica a la teoría política, en la medida en que la política gire alrededor del debate.

Sin embargo, esta objeción confunde dos planos diferentes. Por más que la teoría política trate sobre la política y sea política ella misma, no por eso deja de ser teoría. Hasta el propio Carl Schmitt, autor consciente si los hay del carácter polémico de los conceptos políticos, no escribió Un sino El Concepto de lo Político, porque pretendía tener razón sobre el carácter polémico de los conceptos políticos. En sus propias palabras: "Mi actividad era el trabajo de investigación científica, que no se detiene en resultado alguno, sino que utiliza todo conocimiento ganado como estímulo para un conocimiento ulterior". ${ }^{4}$

3 Biset, ciertamente, hace referencia a la infalibilidad del test, pero dicha infalibilidad se basa en que el test parte de una caracterización adecuada del republicanismo clásico. Con lo cual, lo que está en cuestión es la normatividad o corrección del retrato, y por lo tanto la del test.

4 Schmitt, C., "Antwort an Kempner", en Maschke, G. (ed.), Staat, Großraum, Nomos: Arbeiten aus den Jahren 1916 bis 1969, Berlín, Duncker \& Humblot, 1995, p. 453. Ciertamente, esta declaración es más que conveniente para Schmitt, particularmente en Nuremberg luego de su intervención durante el nazismo. Sin embargo, aunque supusiéramos que se trata de hipocresía, esta última es siempre un homenaje a la sinceridad: la hipocresía tiene sentido solo si, a su vez, tiene sentido sinceramente aquello que afirmamos hipócritamente. Por lo demás, el título de la colección de Duncker \& Humblot en la que apareció la segunda 
Por supuesto, no hace falta remontarse hasta las alturas de la teoría para toparse con esta cuestión. Todo militante político cree que su causa es la correcta, y por eso milita por ella, no por otra. Esta fenomenología de la corrección, o de la normatividad si se quiere, es característica de los seres humanos.

Entonces, ante la pregunta que se formula Biset, "qué puede ser una lectura de la tradición que habilite el debate y no lo clausure" (sección 3), mi respuesta es que aquí estamos, debatiendo sobre el libro, y a menos que debatiéramos por razones solamente expresivas, lo hacemos porque ambos pretendemos tener razón, ofreciendo argumentos en defensa de nuestra posición, etc. Salvo que nos interese debatir por debatir, toda pretensión de corrección apunta a clausurar el debate, al menos hasta que aparezcan nuevos argumentos.

Biset parece suponer además que la pretensión de corrección o normatividad es paradójica: "La necesidad de calificar el retrato sugiere que hay buenos y malos retratos, fieles o infieles” (sección 3). Sin embargo, aquí la "paradoja" la comete asimismo Biset, ya que según él mi retrato del republicanismo no es el adecuado-y de ahí su crítica-. El propio Biset cree además seguramente que su retrato del libro es fiel al libro, ya que de otro modo no tendría sentido su crítica.

Dicho sea de paso, con mucha razón, en relación a la distinción entre la escuela oxoniense y cantabrigense ( $R P, \mathrm{pp} .13-19)$, Biset sostiene que para que la discusión tenga sentido, primero habría que "definir qué puede significar 'comprender"' (sección 2). En aras de la argumentación, voy a suponer que esta discusión tiene sentido, esto es, que nos estamos comprendiendo y de ahí el desacuerdo, y por lo tanto usamos la misma noción de comprender, que para decirlo con muy pocas palabras, le otorga un lugar privilegiado a la intención de la persona que se está expresando. La

edición de El concepto de lo político (1932) es: “Tratados y discursos científicos sobre filosofía, política e historia de la cultura”. Y en la última edición, que corresponde a la versión italiana (1971), Schmitt insiste en que que "el impulso [de su tesis del criterio de lo político] es científico" (Schmitt, C., Der Begriff des Politischen. Synoptische Darstellung der Texte, ed. Marco Walter, Berlín, Duncker \& Humblot, 2018, p. 53). 
intención de Biset es la de mostrar algunos defectos de Razones Públicas, la mía (en esta respuesta) es la de contestarle ${ }^{5}$.

Finalmente, Biset hace referencia a "la revolución tecnológica y el cambio climático" (sección 4), supongo que para mostrar que el republicanismo clásico no trata esos temas. Hoy podríamos agregar pandemias globales a la lista. Sin embargo, nuevamente, el propósito central del libro es ofrecer un retrato fiel a su objeto. Quizás el objeto no es tan atractivo, pero de ahí no se sigue que el retrato no sea fidedigno.

\section{Fuego amigo}

En sus "Notas arendtianas sobre La República de Rosler", Paula Hunziker muestra sus reservas acerca del retrato ofrecido en el libro, sin dejar de sugerir cierta simpatía por el republicanismo, por lo cual se trata de un trabajo ideal para iniciar la transición desde la discusión sobre cómo está hecho el retrato hacia qué es el republicanismo.

Hunziker establece "tres cuestiones". En primer lugar, propone detenerse "en la idea arendtiana de pensar juntos el concepto republicano clásico de 'debate político' y el desempeño de la 'facultad de juzgar", "así como en la posibilidad de su actualización bajo condiciones de 'modernidad”. La preocupación por las pocas posibilidades que tiene el republicanismo clásico de renacer en nuestra época reaparece cuando la autora se refiere a la necesidad de "sopesar el alcance-y la posible actualización-de las tesis republicanas" y nos advierte que "la posibilidad de traer al presente el modelo republicano clásico debe retomar el problema de la virtud de la participación política como tal” (sección 1).

En segundo lugar, Hunziker propone "otra lectura de la libertad republicana clásica, una que pone en el centro la idea de participación del pueblo". En tercer y último lugar, sugiere "revisar la ejemplaridad del Bruto republicano" (introducción).

5 Ciertamente, la intención no es constitutiva de la corrección de lo que uno hace, pero sí es determinante de la comprensión de aquello que estamos haciendo. 
Voy a tratar de responder a estas tres cuestiones. En primer lugar, estoy completamente de acuerdo en que el planteo republicano es muy demandante, y comparto, cada día más, las dudas acerca de sus posibilidades de realización en el mundo contemporáneo. Al final del capítulo 2, en el libro traté de mostrar por qué, sin embargo, no es imposible que un discurso político que tiene como presupuesto fundamental a la virtud pueda tener éxito, aunque no por eso es probable que lo tenga y mucho menos en nuestra época.

Así y todo, creo que el modelo clásico del republicanismo sigue siendo una propuesta que sigue planteando muchas cuestiones relevantes para la agenda de nuestra época, desde la noción de libertad hasta la crisis de la república, pasando por la necesidad de contar con agentes capacitados en la toma de decisiones políticas, el control de los actos gubernamentales, la importancia del debate, la autoridad de la ley, el patriotismo, etc.

Hunziker se detiene en Arendt no solo para plantear las dificultades de realización contemporáneas del republicanismo, sino además y fundamentalmente para devolverle a Hannah Arendt el sitial que supo tener antes de que el neo-republicanismo de Philip Pettit (y otros) la relegara. Hunziker, así y todo, afortunadamente concede que "la lectura de Rosler es generosa y amplia, reconociendo en varios pasajes del libro el aporte de Arendt al redescubrimiento contemporáneo del republicanismo" (sección 2).

La objeción de Hunziker sin embargo es que Razones Públicas "acepta el diagnóstico de Pettit en dos sentidos. Por un lado, destacando la lectura arendtiana del mundo romano (sin tener en cuenta la fuente griega). Por otro lado, más allá de Arendt: estableciendo una jerarquía normativa-no sólo una diferencia conceptual-de la libertad como participación en los asuntos comunes respecto de la libertad como no-dominación, esto es, como 'no interferencia arbitraria' en la vida de cada uno" (sección 2). En otros términos, Hunziker teme que "la distinción entre libertad republicana y libertad positiva, ... una distinción conceptual a priori, deje de lado experiencias históricas republicanas ejemplares y su relación hermenéutica” (introducción).

Mi respuesta es que, en primer lugar y para ser estrictos, si acepto el diagnóstico de Pettit, esto no se debe a que la tradición romana del republicanismo siga a Pettit, sino a que Pettit sigue a la tradición romana del repu- 
blicanismo. Es por eso que la teoría de Pettit es neo-romana. En cambio, la teoría política de Arendt es en todo caso griega o neo-griega. En una época se solía hablar de modo indistinto tanto de la república romana como de la griega, lo cual explica por qué, por ejemplo, John Pocock, basándose en Arendt, incorporara a Aristóteles al panteón de los pensadores republicanos $^{6}$. Sin embargo, si bien el republicanismo ha usado a Aristóteles, ciertamente de ahí no se sigue que Aristóteles haya sido republicano ${ }^{7}$.

Por un lado, Aristóteles era bastante liberal respecto a las formas de gobierno, ya que no tenía problemas en incluir a la monarquía dentro de las formas correctas de gobierno, mientras que el republicanismo clásico romano era claramente anti-monárquico. Por el otro, la teoría política normativa por así decir de Aristóteles, al menos la que se refiere a la polis ideal, entendía a la política como una actividad constitutiva del bien humano, antes que como una manera de defenderse de la no dominación.

En el republicanismo clásico (o romano), en cambio, la voz cantante la tiene la libertad como no dominación. Ciertamente, dicha libertad no es incompatible con el auto-gobierno y la participación popular. En realidad, el papel que juega la virtud cívica en el republicanismo clásico se explica en gran medida debido a que los ciudadanos en una república no solo tienen un sistema político, sino que son ese sistema político, sin que por eso dejen de entender a la libertad como no dominación. En todo caso, el valor de la participación se debe a la no dominación, y no al revés.

Por el otro lado, Hunziker habla de "la recuperación romana del mundo clásico griego" (sección 2), lo cual se puede predicar tal vez respecto de Cicerón, pero no de la práctica romana republicana clásica, que data de varios siglos antes de Cicerón, y que en el mejor de los casos fue contemporánea de la obra de Platón y de Aristóteles. Después de todo, Razones Públi-

6 Véase Pocock, J., The Machiavellian Moment: Florentine Political Thought and the Atlantic Tradition, Princeton, Princeton University Press, 1975, pp. 335, 527, 550, inspirado a su vez en Arendt, H., The Human Condition, Chicago, The University of Chicago Press, 1958, pp. 22-28.

7 Véase Razones Públicas, p. 70, n. 10, y, v.g., Rosler, A., "Civic virtue: citizenship, ostracism, and war", en Destrée, P. y Deslauriers, M. (eds.), The Cambridge Companion to Aristotle's Politics, Cambridge, Cambridge University Press, 2013, pp. 144-145. 
cas trata sobre el discurso republicano clásico "en el sentido más amplio de la extensión que incluye conceptos, prácticas, instituciones, etc." (RP, p. 11).

De ahí que no haya razones para creer que el libro parte de "una distinción conceptual a priori" (introducción). Por supuesto, tal como se puede constatar no solo en el libro sino en las consideraciones vertidas más arriba en respuesta al trabajo de Biset, el retrato tiene que dejar de lado "experiencias republicanas ejemplares" en la medida en que esos ejemplos no correspondan al modelo clásico.

Me veo entonces obligado a insistir en que, aunque entiendo la sospecha de que el retrato del republicanismo clásico que aparece en Razones Públicas no sea sino una de las múltiples instancias del expresionismo o impresionismo modernos, casi todas las notas del libro tratan de mostrar por qué la teoría política descripta es la del republicanismo clásico, y no la mía. En todo caso, puede ser mía en el sentido de que tal vez estoy de acuerdo con ella, pero no porque yo la haya inventado.

Quizás, entonces, sea preferible una concepción arendtiana, "più greca che italiana" como dicen los guardaespaldas sicilianos de Michael Corleone en "El Padrino", según la cual "Los hombres participan en la res publica no porque no quieran ser dominados, sino porque son libres cuando actúan con otros" (sección 2), pero, aunque sea preferible, no por eso es el modelo del republicanismo romano clásico.

Alguien podría objetar que así y todo Arendt es mencionada frecuentemente en un libro sobre el republicanismo clásico, lo cual sería inadmisible a la luz de la distinción tajante entre el republicanismo clásico romano y el griego. Sin embargo, Arendt emerge dos o tres veces en el capítulo 2 sobre la virtud y fundamentalmente varias veces en el capítulo 4 sobre la ley, ya que si bien la teoría política de Arendt es bastante griega, su teoría jurídica es distintivamente romana ("più italiana che greca", al revés que en "El Padrino") ${ }^{8}$.

8 Ciertamente, alguien podría objetar que según este criterio Aristóteles tampoco debería figurar en un libro sobre el republicanismo clásico romano. Sin embargo, Aristóteles es traído a colación en el libro no porque él sea republicano, sino porque su obra permite ilustrar algunas cuestiones típicamente republicanas, como la virtud cívica o la tiranía. Sobre la diferencia entre el republicanismo romano y el griego véase Nelson, E., The Greek 
Finalmente, Hunziker retoma, por así decir, un punto de Biset sobre la precisión del retrato al sostener que Razones Públicas "elimina una posibilidad del republicanismo", ya que se trata de un retrato incompatible con el "cesarismo". Hunziker cree que es Bruto, y no César, quien pudo haber destruido la república (introducción), por lo cual se podría inferir que no es el cesarismo sino el "brutismo" el que es incompatible con la receta republicana clásica.

Con razón, Hunziker hace referencia a un "espectro del republicanismo, en todas sus variantes, más o menos populares, más o menos aristocráticas” (sección 3), que de hecho figura en el capítulo 3 de Razones Públicas (pp. 151-161), bajo el título: "en el principio era el conflicto". Me permito citar el comienzo de dicha sección: "Para el discurso republicano clásico, la política no se agota en el debate sino que la participación directa de la ciudadanía es decisiva para la república, a tal punto que se puede hablar de una sensibilidad republicana por la dinámica política conflictiva, la cual no termina de cristalizarse jamás" ( $R P$, p. 151). Sin embargo, esto no se debe a que la tradición romana clásica entendía la participación política como un fin en sí mismo, sino a que, nuevamente, era una herramienta indispensable en el combate contra la dominación. Y es este mismo combate contra la dominación lo que vuelve incompatible al republicanismo con el cesarismo. Quizás, otra vez, haya muy buenas razones para defender al cesarismo, pero esas razones no son republicanas en el sentido clásico de la expresión.

Hunziker tiene razón una vez más al sostener que las acciones de Bruto no tuvieron éxito, si no es que fueron contraproducentes, ya que no hicieron revivir la república (sección 3). Pero en ese caso, el punto es que la república ya estaba muerta. Matar a César fue, como se dice en inglés, azo-

p. 160). Mientras que la tradición romana gira alrededor de la no dominación, la griega en cambio gira alrededor de la felicidad humana a través de la contemplación. Se podría decir que ambas tradiciones se interesan por la justicia, aunque siguiendo concepciones diferentes. Mientras que la visión romana sostiene que se trata de dar a cada uno lo suyo, la griega en cambio cree en una organización de los recursos según pautas naturales. En todo caso, el énfasis griego en la justicia y el bienestar humanos hace que las cuestiones institucionales características del modelo romano pasen a segundo plano. Sin embargo, una teoría de la justicia que suponga acuerdos sustantivos no puede dar cuenta de la autonomía del conflicto político y la consecuente necesidad de contar con procedimientos e instituciones que permitan resolver o al menos canalizar el desacuerdo al respecto. 
tar un caballo que ya estaba muerto. En la autopsia, así y todo, todavía se puede comprobar que en Roma estaba prohibido y castigado con la muerte aspirar a la monarquía e incluso pronunciar la palabra (v. $R P, 266-271$ ).

Yendo a la "La exigencia retórica in utramque partem y el tema del escepticismo", Guillermo Lariguet ofrece un muy erudito desarrollo de la relación entre retórica y escepticismo, sin dejar de presentar "ejemplos contemporáneos de la política argentina”. Dado que examina "el escepticismo fuerte, especialmente en política" (sección 5), el de Lariguet es un complemento más que bienvenido para el escepticismo débil o metodológico examinado en el libro ( $R P, \mathrm{pp} .124,128)$. Lariguet termina señalando con mucha razón la existencia de una "incompatibilidad entre el escepticismo-especialmente fuerte-y la política dado el impulso a la acción que subyace a ésta" (sección 6).

Romina Rekers, por su parte, quiere ir "Más allá del republicanismo clásico", pero siempre por el camino republicano, e inicia su fuego amigo con la siguiente salva: "El problema de combinar un retrato del republicanismo clásico con la pretensión de evaluar instituciones, acciones y discursos o diseñar una agenda republicana es que el retrato ofrecido tiene limitaciones o vaguedades que hoy ya se encuentran superadas por el neorepublicanismo" (sección 1).

Sin embargo, tal como hemos visto más arriba, la idea de "agenda" a la que se refiere el libro es la de "un recordatorio de cuestiones que toda persona interesada en el republicanismo se debería plantear" (RP, 10)”. De ahí que mi punto no es que el republicanismo clásico sea la única solución a todos los problemas.

Por supuesto, estoy completamente de acuerdo con Rekers en que "como la mayoría de las grandes corrientes del pensamiento político, el republicanismo es una tradición en constante evolución” y no me extrañaría que, como dice Rekers, el "neorepublicanismo" presente "un mejor servicio [que el prestado por Razones Públicas] a la hora de ofrecer razones a favor de la adopción de la libertad republicana como ideal regulativo" (sección 1). Sin embargo, el propósito del libro no es el de reemplazar al neorepublicanismo, sino describir el republicanismo clásico, lo cual es a su modo una forma de proponer una agenda de cuestiones que pueden ser de interés en nuestros días. 
De ahí que Rekers tenga mucha razón cuando dice que "el retrato ofrecido por Rosler del republicanismo clásico" es "un retrato desactualizado del republicanismo" (sección 1). En rigor de verdad, tiene que serlo, ya que la agenda propuesta por el libro se basa en un retrato del republicanismo clásico, que por definición pertenece al pasado. Por supuesto, hasta los retratos clásicos pueden actualizarse ya que pueden mejorar una descripción anterior, pero, sin que cambie el objeto descripto, en la medida en que se trate de una nueva interpretación y no de una nueva obra. Una cosa es el republicanismo clásico y otra bastante distinta el neo-republicanismo.

Rekers también tiene mucha razón en que "la tarea meramente descriptiva de una tradición anclada en un contexto temporal y espacial resulta insuficiente" (sección 1), si lo único que nos interesa es qué hacer con el republicanismo hoy en día. Pero si lo que nos interesa hacer además es entender en qué consiste el republicanismo clásico-entre otras cosas para ver su relevancia actual-no hay otra alternativa que proponer una descripción que resulta "insuficiente", de otro modo estaríamos cometiendo la trampa del anacronismo, es decir, no estaríamos hablando del republicanismo clásico sino del actual.

En resumen, lo que para Rekers parece ser un defecto, en el fondo es un cumplido. La lealtad principal del libro es para con el republicanismo clásico, no para con el neorepublicanismo.

Yendo a las críticas específicas de Rekers, por ejemplo: "Rosler parece no distinguir claramente entre libertad en un sentido metafísico y libertad política” (sección 2), quisiera citar en mi defensa el párrafo siguiente:

la libertad negativa suele ser complementada con cierta dosis de elegibilidad, para que la libertad de poder actuar de otro modo-que solía ser llamada libre albedrío—no sea confundida con la libertad negativa protegida por el liberalismo. De hecho, hasta los regímenes totalitarios suponen que sus súbditos pueden actuar de otro modo, son 'libres' en sentido metafísico, por así decir, y por eso mismo (en el mejor de los casos) los amenazan volviendo inelegibles o poco atractivas ciertas alternativas para sus súbditos (RP, p. 37). 
El ejemplo de "la célebre capacidad de Don Corleone en 'El Padrino I' (1972) para proponer ofertas que no pueden ser rechazadas", tampoco tuvo el efecto esperado, es decir, el de distinguir entre la libertad metafísica y la libertad políticamente relevante. Otro tanto se puede decir del siguiente ejemplo shakespeariano: "Quienes, como... Casio..., insisten en que mediante el suicidio podemos 'sacudir a voluntad esta parte de la tiranía' que soportamos, tienen razón en términos conceptuales ya que podemos quitarnos la vida, pero se trata de una verdad políticamente absurda" $(R P, 37)$.

Hablando de la caracterización de la libertad como no dominación característicamente republicana y en relación a la discusión sobre la esclavitud, Rekers indica que "Rosler sostiene que lo problemático para la libertad es estar sujeto al poder discrecional de alguien. De acuerdo con esta visión de lo que implica la dominación, la interferencia dominadora es aquella que se ejerce como consecuencia de poseer un poder discrecional. De este modo, en su reconstrucción del republicanismo clásico Rosler adopta una posición sobre lo que implica la interferencia arbitraria que en el debate neorepublicano ha quedado atrás" (sección 4). Si bien no lo aclara específicamente, creo que Rekers tiene en mente el pasaje siguiente: "Es la discreción del amo la que decide sobre la suerte del esclavo. Alguien que depende de la discreción de otra persona puede ser tratado correctamente e incluso estar contento, pero no por eso deja de ser una persona dominada o esclava" $(R P, 54)$.

Le agradezco mucho a Rekers por haberme llamado la atención sobre este pasaje, ya que, leído fuera de contexto, puede prestarse al siguiente malentendido, a saber: el republicanismo clásico era un enemigo declarado de la discreción sin más. Sin embargo, en primer lugar, el pasaje señalado aparece en el contexto de una discusión sobre la esclavitud. En segundo lugar, tal como surge del retrato ofrecido en el libro, el republicanismo clásico no tenía problema alguno con la discreción en sí misma, a tal punto que la dictadura es una creación romana. Lo mismo se puede decir de todas las magistraturas romanas, en la medida en que contaban con autoridad, esto es, en la medida en que se trate de razones independientes de contenido en general, lo cual implica una grado considerable de discreción $(R P$, pp. 182-188). De hecho, tal como figura en el libro, "la política normal no está libre de la discreción de los funcionarios, ya que son ellos quienes 
ejercen su juicio decidiendo cómo aplicar el derecho y qué se debe hacer cuando el derecho no se pronuncia sobre la cuestión" ( $R P$, p. 280).

Lo que sí temía el republicanismo clásico, y supongo que sucede lo mismo con el neo-republicanismo, era la discreción arbitraria, que el libro-algo anacrónicamente-designa como "cesarismo" y que es tratado en el capítulo 6. Lo que está en juego entonces para el republicanismo clásico es cuándo la discreción está justificada, no la discreción en sí misma.

\section{Fuego enemigo}

En "El rol de las virtudes en el republicanismo", Anna Richter muestra algunas reservas sobre las virtudes en la sociedad contemporánea, por lo cual su trabajo ofrece una muy propicia ocasión para iniciar la transición hacia la discusión sobre la superioridad del republicanismo respecto a otros discursos políticos, esto es, para pasar de Hunziker y Rekers a Venezia y González del Solar.

Con esto no quiero implicar que Richter no sea republicana en general (algo me dice que ella siente al menos cierta simpatía por el republicanismo), sino que al menos en esta ocasión se muestra razonablemente escéptica al respecto, particularmente acerca de si "se pueden trasladar las exigencias de virtuosidad del republicanismo clásico a nuestros tiempos" (sección 1).

Estoy completamente de acuerdo con Richter en que "se puede percibir una diferencia importante entre la república clásica” tal como es presentada en el libro "y nuestras sociedades contemporáneas" (sección 5). En gran medida, ese es el punto del retrato ofrecido en el libro. Por las mismas razones, sin embargo, el gran desafío de toda teoría republicana en las condiciones actuales de nuestra sociedad es cómo lograr el mínimo imprescindible de virtud cívica que requiere toda república, sin recurrir, por ejemplo, a instituciones tales como la censura, cuya tarea principal no era tanto o solo la de coartar la libertad de expresión, sino la de velar por el carácter virtuoso de los ciudadanos ${ }^{9}$. En nuestro tiempo, quizás estemos de

9 Facebook, por ejemplo, ha designado un comité de expertos en derechos humanos, particularmente en la libertad de expresión, que decide qué se puede expresar en dicha red social. 
acuerdo en que la educación cívica sea obligatoria para menores de edad, pero no tanto para quienes hayan alcanzado la mayoría de edad.

La posibilidad no es el único problema que tiene la virtud cívica, sino que por otro lado parece ser innecesaria, lo cual parece indicar una contradicción en el retrato esbozado en el libro $(R P, 58-66)$. Tal como sostiene Richter, el argumento hegeliano del reconocimiento que "requeriría precisamente la aceptación de la libertad como no dominación y llevaría por ende a la implementación del republicanismo", parece implicar que "no haría falta una ciudadanía muy virtuosa para establecer ese sistema político, sino simplemente personas interesadas en ser reconocidas como sujetos" (sección 4.1).

Sin embargo, esta observación supone que la virtud y el auto-interés son incompatibles, mientras que para la tradición republicana no lo son, tal como lo muestra el final del capítulo 2 sobre el papel de la identidad en la virtud cívica, que retoma precisamente el argumento del reconocimiento ( $R P$, pp. 92-111). En todo caso, el planteo de Richter, como el de Rekers y el de Hunziker, son un muy sano recordatorio de algunas de las varias dificultades que tiene el republicanismo clásico para renacer en el mundo contemporáneo.

Yendo finalmente a los "enemigos" del republicanismo, el trabajo de Luciano Venezia ("El republicanismo frente al liberalismo igualitario"), defiende la tesis según la cual el liberalismo igualitario no tiene nada que envidiarle al republicanismo en la lucha contra la dominación.

Venezia se queja de que los lectores del libro se llevan la impresión de que "la justicia debe estar únicamente determinada por la libertad, razón por la cual desarrollar un análisis adecuado del concepto de libertad se vuelve una tarea fundamental para articular y defender una concepción sustantiva de la justicia distributiva". En realidad, agrega Venezia, "esta forma de plantear las cosas no parece realmente adecuada y en todo caso no describe la manera de proceder de los defensores contemporáneos del liberalismo, especialmente del liberalismo igualitario" (sección 2).

En el fondo, la crítica de Venezia consiste en que el libro no discrimina adecuadamente entre las diferentes concepciones imperantes en el mercado liberal, lo cual hace que, por ejemplo, el libertarianismo de Nozick sea confundido con el igualitarismo de Rawls (sección 2). 
Ahora bien, mi punto en Razones Públicas es que si o cuando hablamos de libertad como no dominación el republicanismo en general está mejor preparado que el liberalismo para tratar cuestiones como la de la distribución del ingreso, ya que la idea misma de libertad republicana sin más prolegómenos incluye la noción de no dominación. En otras palabras, mientras que para el liberalismo la discusión sobre la dominación es un efecto colateral o indirecto de la libertad, o en todo caso requiere de un paso extra, para un republicano no queda otra alternativa que tratar el tema desde el minuto cero.

Sin embargo, estoy completamente de acuerdo con Venezia en que de ahí no se sigue que el liberalismo no tenga recursos para combatir la no dominación. En realidad, "los liberales de corte igualitario consideran que, además de la libertad como no interferencia, hay asimismo otros valores que deben informar las principales instituciones de una sociedad justa, incluyendo por supuesto la igualdad" (sección 2). Por otro lado, tal como figura en el libro, $(R P, 160-161)$, el republicanismo clásico romano creía que toda restricción a la propiedad privada en la forma de un impuesto directo era tiránica sin más, con lo cual el liberalismo rawlsiano, por ejemplo, hubiera sido considerado totalmente anti-republicano por Cicerón.

En rigor de verdad, es el republicanismo contemporáneo o neo-republicanismo el que sostiene que la libertad como no dominación puede ser útil en la discusión sobre la teoría de la justicia entendida en términos de la distribución del ingreso. Si la genealogía es irrelevante para el alcance de una teoría política (después de todo, el republicanismo clásico no tuvo problemas en creer que la defensa de la libertad como no dominación no era sino la otra cara de la defensa de la esclavitud, v. $R P, \mathrm{p} .64$ ), entonces quizás el republicanismo tenga éxito en su combate contra la dominación incluso en el ámbito económico y social.

Hablando de lo cual, en "Republicanismo y vida privada", Matías González del Solar se pregunta: “¡puede la idea republicana de libertad como no-dominación, extendida más allá del ámbito político, ser respetuosa de la identidad moral de aquellos ciudadanos que se conciben a sí mismos como constituidos en parte por sus vínculos comunitarios?". Lo que le preocupa a González del Solar es que "pretender extender la concepción de libertad más allá del ámbito político deja desprotegidas a aquellas personas que no 
conciben a la libertad como un valor que deba ser perseguido en su esfera privada" (sección 1).

González del Solar advierte dos grandes problemas del republicanismo: "trato deficitario de los vínculos comunitarios" (sección 4.1) y "déficit en la satisfacción de la neutralidad de objetivo" (sección 4.2).

Como ya hemos visto, el republicanismo clásico no era tan demandante en su lucha contra la no dominación, ya que toleraba y hasta exigía la dominación en varios ámbitos, tal como lo muestra su defensa de la esclavitud en algunos casos. De hecho, a pesar de girar alrededor de la idea de libertad como no dominación, el republicanismo clásico suponía que el sentido mismo de que la no dominación fuera un valor era que la dominación existiera no solo en términos conceptuales y normativos, sino además ontológicos por así decir. Para el republicanismo clásico, si no hubiera esclavitud, no tendría sentido ser libre.

Rousseau presenta la cuestión del modo siguiente:

¡Qué! ¿La libertad no se mantiene que con el apoyo de la esclavitud? Puede ser. Los dos extremos se tocan. (...). Existen situaciones desafortunadas en las que no se puede conservar la libertad más que a expensas de la de otro, y donde el ciudadano no puede ser perfectamente libre si el esclavo no es extremadamente esclavo. Tal era la situación de Esparta. Para Uds., pueblos modernos, no tenéis esclavos, pero lo sois vosotros; vosotros pagáis su libertad con vuestra esclavitud ${ }^{10}$.

Por lo cual, en rigor de verdad, el republicanismo clásico al menos no imponía la no dominación dentro del ámbito privado o doméstico, lo cual puede ser un arma de doble filo, tal como lo muestra el ejemplo de la esclavitud. Sin embargo, González del Solar tiene razón en que no todas las culturas están dispuestas a someter el ámbito privado al ideal de la no dominación. La pregunta que nos debemos hacer es si es suficiente que una

${ }^{10}$ Rousseau, J.-J., Du Contract Social, ed. R. Derathé, en Oeuvres complètes, París, Gallimard, 1964, p. 431, la traducción es nuestra. Para Nietzsche, es precisamente la conexión conceptual que existe entre la libertad y la esclavitud lo que hace que la libertad en el fondo sea una noción servil. Véase Geuss, R., History and Illusion in Politics, Cambridge, Cambridge University Press, 2009, p. 85. 
práctica o institución sea cultural para que obtenga nuestro asentimiento, sin desconocer que el propio republicanismo es una cultura entre otras.

Yendo al segundo déficit republicano, González del Solar también tiene razón en que el republicanismo no es exactamente neutral. Sin embargo, lo que traté de mostrar en el libro es que la exigencia de virtud cívica no es necesariamente inquisitorial, sino que en todo caso es moralmente anodina, ya que toda teoría política implica la inclusión de algunos valores, principios, instituciones, etc., en perjuicio de otros $(R P, 12,72-74)$.

En realidad, si, como bien dice González del Solar apoyándose en Pettit, "un acto no es arbitrario si el agente al tomar la decisión que interfiere en la vida de un individuo tuvo en cuenta el bienestar, la visión del mundo, los intereses u opiniones del afectado" (sección 3.b), entonces si lo que parece ser dominación en realidad tiene en cuenta "el bienestar, la visión del mundo y los intereses u opiniones del afectado", entonces en tal caso el propio republicanismo debería abstenerse de intervenir en el ámbito privado.

\section{4. ¿Qué queda de Razones Públicas?}

En la introducción a esta discusión, los editores formulan una pregunta más que pertinente, a saber, si en vista de los comentarios vertidos en los trabajos que componen la discusión, el autor podrá "sostener su teoría tal como la sostuvo en Razones Púbicas o deberá conceder, reformular e incluso renunciar a algunas de sus tesis". En otras palabras, la cuestión es: “QQué queda de su propuesta de reconstruir el republicanismo clásico para su uso en el debate político actual después de los desafíos aquí presentados?" (introducción). Como se puede apreciar, estas dos preguntas indican las dos grandes cuestiones de toda la discusión: ¿el retrato es fiel? y ¿es atractivo todavía hoy en día?

Tal vez una breve recapitulación de la genealogía del retrato ayude a entenderlo mejor. Hace unos años, gracias a la editorial Hydra, tuve la oportunidad de traducir al español los Elementos Filosóficos de Hobbes, un libro más conocido como De Cive $e^{11}$. En aquella ocasión, y tras los pasos

${ }^{11}$ Hobbes, T., Elementos Filosóficos. Del Ciudadano, Buenos Aires, Hydra, 2010. 
de Quentin Skinner, en el prólogo del libro ("El enemigo de la república”) traté de explicar la teoría política de Hobbes tal como es presentada en De Cive en términos de una crítica al republicanismo clásico.

Para poder exponer dicha crítica, primero tuve que hacerme una idea articulada de cuál era el blanco de la misma. De ahí que en el prólogo del libro figuren cuestiones como ciencia y retórica como dos métodos en disputa, la libertad, la moralización del estado de naturaleza, la autonomía de la política, el miedo al enemigo, la noción de pueblo, la estetización republicana de la política, la guerra justa, el derecho penal del enemigo, etc.

Mientras que, siguiendo la tradición humanista, en aquel prólogo traté de mostrar los flancos débiles del republicanismo clásico, en Razones Públicas aproveché la ocasión para responder las críticas de Hobbes, lo cual hizo, a su vez, que me concentrara en el esqueleto conceptual indispensable de dicha tradición.

Volviendo entonces a la primera pregunta acerca de qué queda del retrato, creo que si bien esta discusión me ha dado una gran oportunidad para revisar el cuadro presentado en el libro, las buenas noticias son que la descripción sigue básicamente en pie. Ciertamente, el retrato quizás no sea atractivo, pero la cuestión es si la imagen retratada provoca rechazo precisamente porque es fiel al modelo que representa. Cabe recordar que los modelos que posaron para el retrato fueron principalmente Tito Livio, Cicerón, Salustio y Maquiavelo, por supuesto que con la ayuda fundamentalmente estilística de otros autores que creo pueden ser muy útiles para ayudarnos a entender mejor el retrato clásico.

En cuanto a la segunda pregunta, “¿Qué queda de su propuesta de reconstruir el republicanismo clásico para su uso en el debate político actual después de los desafíos aquí presentados?", la discusión en Río Ceballos confirmó mi sospecha, nacida no mucho después de la publicación de Razones Públicas, de que el autor peca de cierta ingenuidad al sostener que "el republicanismo tiene los recursos necesarios para precisamente poder mantenerse en guardia y ejercer un alto grado de autocrítica" $(R P, 19)$.

Aquí me voy a limitar a agregar otro talón de Aquiles-si es que pueden existir varios-del republicanismo clásico, a saber, el derecho penal. La idea de libertad como no dominación, es decir la idea de que alguien puede estar en prisión y ser libre a la vez en la medida en que la detención 
no sea arbitraria, explica por qué Rousseau pudo sostener que "En Génova se lee delante de las prisiones y en los grilletes de los galeotes la palabra Libertas. Esta aplicación de la divisa es hermosa y justa. En efecto, sólo los malhechores de toda condición impiden al ciudadano ser libre. En un país en que todas estas gentes estuvieran en galeras se gozaría de la libertad más perfecta"12.

La moralización de la noción de libertad explica a su vez por qué algunos criminales son tratados como enemigos-al menos en el sentido del así llamado derecho penal del enemigo-, por qué en tales casos el derecho positivo es reemplazado por el derecho natural, y finalmente por qué el criminal o enemigo no sea tal solo en relación a un ordenamiento jurídico en particular, sino en relación a toda la Humanidad ${ }^{13}$.

Alguien podría sostener que si el talón existe, entonces lo que está en cuestión entonces no es solo el atractivo del modelo, sino el modelo en sí mismo, ya que en el capítulo 4 sobre la ley de Razones Públicas no figuran ninguno de los rasgos del republicanismo penal clásico que han renacido últimamente (la oscilación entre el delito y la guerra, entre el derecho positivo y el natural, y la sinécdoque).

Lo único que puedo decir aquí y ahora en mi defensa es que, en rigor de verdad, el libro no omite esta cuestión, sino que la trata en el capítulo 5 sobre la patria, particularmente las secciones sobre la república en guerra, y en el capítulo 6 sobre César, especialmente las secciones sobre las herramientas de las que disponía la república clásica para responder ante la crisis (dictadura, senatus consultum ultimum, etc.), amén de la referencia al delito de maiestas, que con el tiempo se convertiría en el crimen de lesa majestad, el antecesor conceptual del delito de lesa humanidad (v. $R P$, p. 272, n. 35). Como se puede apreciar, hoy se tratan dentro del derecho penal cuestiones que en el discurso clásico eran características de la guerra y de la crisis de la república, pero no de la administración de justicia.

12 Rousseau, J. -J., op. cit., p. 440.

${ }^{13} \mathrm{Al}$ respecto, véase, por ejemplo, Rosler, A., "Si Ud. quiere una garantía, compre una tostadora.' Acerca del punitivismo de lesa humanidad", En Letra: Derecho Penal, 3 (5), 2017, pp. 62-102, y "El Estado de Derecho caído en 'Batalla", En Letra: Derecho Penal, 5 (7), 2019, pp. 20-34. 
En conclusión, el renacimiento del republicanismo indica la vitalidad de un discurso literalmente milenario, y a juzgar por la discusión que ha provocado-por suerte al menos para quienes se dedican a la teoría política y del derecho-seguiremos teniendo republicanismo para rato.

\section{Bibliografía}

Arendt, H., The Human Condition, Chicago, The University of Chicago Press, 1958.

Geuss, R., History and Illusion in Politics, Cambridge, Cambridge University Press, 2009.

Hobbes, T., Elementos Filosóficos. Del Ciudadano, Buenos Aires, Hydra, 2010.

Nelson, E., The Greek Tradition in Republican Thought, Cambridge, Cambridge University Press, 2004.

Pocock, J., The Machiavellian Moment: Florentine Political Thought and the Atlantic Tradition, Princeton, Princeton University Press, 1975.

Rosler, A., “'Si Ud. quiere una garantía, compre una tostadora'. Acerca del punitivismo de lesa humanidad”, En Letra: Derecho Penal, 3 (5), 2017, pp. 62-102,

Rosler, A., "Civic virtue: citizenship, ostracism, and war", en Destrée, P. y Deslauriers, M. (eds.), The Cambridge Companion to Aristotle's Politics, Cambridge, Cambridge University Press, 2013.

Rosler, A., "El Estado de Derecho caído en 'Batalla", En Letra: Derecho Penal, 5 (7), 2019, pp. 20-34.

Rousseau, J.-J., Du Contract Social, ed. R. Derathé, en Oeuvres complètes, París, Gallimard, 1964.

Schmitt, C., "Antwort an Kempner", en Maschke, G. (ed.), Staat, Großraum, Nomos: Arbeiten aus den Jahren 1916 bis 1969, Berlín, Duncker \& Humblot, 1995.

Schmitt, C., Der Begriff des Politischen. Synoptische Darstellung der Texte, ed. Marco Walter, Berlín, Duncker \& Humblot, 2018. 